\title{
Os livros e a vida na poesia de Dora Ferreira da Silva
}

\author{
Books and life in the poetry of Dora Ferreira da Silva \\ Los libros y la vida en la poesía de Dora Ferreira da Silva \\ Enivalda Nunes Freitas e Souza* \\ Erick Gontijo Costa*
}

\section{Resumo}

A partir de um poema de Dora Ferreira da Silva que trata de seu desinteresse pelo romance Ulisses, de James Joyce, este artigo desenvolve uma reflexão sobre o sentido humanizador da arte para a poeta paulista. Além de incursionar por poemas que trazem os mitos de Orfeu e Cassandra como representativos do poder organizador, fundante e humanizador da palavra poética, recobra-se um surpreendente texto de Carl Gustav Jung sobre a referida obra joyceana. Pelos vieses crítico-teóricos, objetiva-se investigar a arte como um construto de vivências ficcionais que refletem o homem em sua temporalidade.

Palavras-chave: Dora Ferreira da Silva, Ulisses, Carl Gustav Jung, Wolfgang Iser.

\begin{abstract}
This article reflects on the humanizing sense of art in the work of poet Dora Ferreira da Silva, based on her poem that deals with her disinterest in James Joyce's Ulysses. Beyond exploration of her works that adopt the myths of Orpheu and Cassandra as the organizing and humanizing principal of her poetry, we recover a surprising text of Carl Gustav Jung on Joyce's work. Through a critical-theoretical approach, this article investigates art as a construct of fictional experiences that reflect man in his temporality.
\end{abstract}

Keywords: Dora Ferreira da Silva, Ulysses, Carl Gustav Jung, Wolfgang Iser.

\section{Resumen}

A partir de un poema de Dora Ferreira da Silva que trata de su desinterés por la novela Ulises, de James Joyce, este artículo desarrolla una reflexión sobre el sentido humanizador del arte para la poeta paulista. Además de incursionar por poemas que tratan los mitos de Orfeo y Cassandra como representativos del poder organizador, fundador y humanizador de la palabra poética, se recobra un sorprendente texto de Carl Gustav Jung sobre la referida obra joyceana. Por los sesgos críticoteóricos, se pretende investigar el arte como un constructo de vivencias ficcionales que reflejan al hombre en su temporalidad.

Palabras clave: Dora Ferreira da Silva, Ulises, Carl Gustav Jung, Wolfgang Iser.

\section{Os livros e a vida: os mapas que os insetos traçam nas folhas}

\author{
Ulisses e o inseto \\ Quando li o Ulisses de Joyce \\ o verão era pungente \\ e as questões. \\ Nem a rede embalava \\ nem o mar aplacava \\ nossos dédalos.
}

\footnotetext{
* Doutora em Literatura Brasileira e professora da Universidade Federal de Uberlândia (UFU), Uberlândia, MG, Brasil. (Dorcid.org/00000001-6012-1224. E-mail: eni@ufu.br.

** Pós-doutorando em Estudos Literários na Universidade Federal de Uberlândia (UFU), Uberlândia, MG, Brasil e professor do Centro Federal de Educação Tecnológica de Minas Gerais (CEFET-MG), Varginha, MG, Brasil. (Dorcid.org/0000-0002-9571-3876. E-mail: erickgcosta@gmail.com.
} 
O vento soprou as areias e então

um inseto pousou no livro

aberto ao meio:

olhitos facetados fitaram-me e foi quando

a leitura findou

na página duzentos e tanto... (Silva, 1999, p. 151)

O título do poema faz pasmar, causa suspensão porque coloca lado a lado o grande e o ínfimo, o técnico e o natural, o racional e o sensível, o herói e o inseto. Primeiro, é o Ulisses homérico da astúcia, das aventuras intermináveis, dos ardis engenhosos e da autoridade real a figura retomada. Mas logo o aventureiro dos primórdios da literatura deságua no moderno, na narrativa que é um labirinto de si mesma, uma obra de Dédalo, aliás, personagem evocado na ficção joyceana. Contudo, a obra que desafia críticos e leitores desde seu lançamento em 1922 não agrada à poeta, que deixa a leitura inconclusa. A grandiosidade não é suficiente, aquele monumental artefato artístico nada lhe diz, é na natureza que a poeta busca resposta. São os olhos fitados, intensamente vivos do inseto, o misterioso tirado da natureza que lhe chamam ao mundo, que a resgatam desse labirinto de linguagem. A mensagem das coisas sensíveis. É a vida que é encarada como enigma. A estrutura poemática divide as duas realidades: por meio do enjambement - "O vento soprou as areias e então / um inseto pousou no livro" - o poema abre-se ao meio, parte-se ao meio, deixa o livro aberto ao meio, cedendo espaço ao vento anunciador da força espiritual que anima a vida. Na anunciação lúdica e afetiva dos "olhitos" facetados do inseto, encerra-se o jogo do texto.

Se um jovem leitor faz uma declaração como essa, a respeito de uma obra literária canônica, se confessa que não conseguiu ler tal romance - o Grande sertão: veredas, por exemplo, empreitada que não se leva a termo a não ser lá pela terceira tentativa, quando não se larga do livro nunca mais - logo se imputa a esse leitor a inexperiência, a escassa bagagem de vida, o acervo bibliográfico ainda limitado e preconceitos advindos de uma formação que assimilou mal a arte moderna. Mas não é o caso de Dora Ferreira da Silva (Conchas/SP, 1918; São Paulo, 2006), poeta que iniciou sua carreira como tradutora de obras alemãs - Rainer Maria Rilke, Carl Gustav Jung e de outros grandes poetas do século XX, além de traduzir os poetas místicos San Juan de la Cruz, Angelus Silesius e Johannes Tauler, quando, em ensaios sobre os traduzidos, pôde aproximá-los da psicologia junguiana. Registre-se, ainda, que a poeta de leitura incompleta de Ulisses foi fartamente premiada pelo Jabuti (três vezes) e recebeu da Academia Brasileira de Letras o Prêmio Machado de Assis, pela poesia completa, em 1999. A formação dessa poeta se completa com a intimidade assombrosa com filósofos como Heráclito, Novalis e Heidegger. Sua linhagem poética remete, por exemplo, ao romantismo alemão de Friedrich Hölderlin, para quem a poesia, mesmo em "tempos de indigência" (Hölderlin, 1999, p. 75), é condição para que haja linguagem e mundo. Portanto, estamos diante de uma poeta erudita, cujo desinteresse por uma obra decisiva da modernidade não se explica por falta de esclarecimento.

Dora não encontrou em Ulisses o que lhe era mais caro em história da arte: a conjunção da natureza e da cultura. Para ressacralizar o mundo esvaziado das potências criativas que confinam com a nomeação do que excede o humano, era preciso buscar a vida pulsante fora da arte sem sentimentos e fora dos museus que não conservam a essência e a textura da natureza, conforme escreve na apresentação da Cavalo Azul, n. 3, revista de arte e poesia dirigida pela poeta dos anos de 1964/1965 a 1989:

A nossa época não permite mais que se entre nos museus. Urge sair deles. Ver e rever os mapas que os insetos traçam nas folhas, seus meandros, círculos, ziguezagues, repetindo-se em caligrafia misteriosa. Olhar as nuvens se comprimindo ou se expandindo em estranhos véus e coroas. Olhar o casulo do bicho da seda, seu tacto macio, a arquitetura das colmeias, os caligrafismos do vento soprando a erva, a tessitura dos raios solares refletidos na água, as estrelas do gelo, as borboletas em cor e desenho dinâmico de voo, a escultura das termiteiras, os veios das pedras que já são, cada uma, um pequeno templo de mão desconhecida. Onde quer que nossos olhos olhem há História da Arte. É uma linguagem cifrada, um mapa do eterno rabiscado, colorido, modelado, erigido no tempo (Silva, s/d, p. 2). 
"Ulisses e o inseto", bem como toda a singular poesia de Dora Ferreira da Silva, expressa essa concepção de mundo baseada na abertura cósmica que se atenta ao recado dos sinais da natureza, ao eterno renascimento solar, à força arquetípica e atemporal dos mitos e, principalmente, à crença de que a linguagem poética e, por extensão, a arte, devem ser praticadas com a intenção consciente e laboriosa de resgatar o homem de sua temporalidade profana e aniquiladora. A palavra poética tem a função de ressacralizar o mundo, devolvendo-lhe a dor, a compaixão e a promessa de alegria e felicidade nesse mundo desconsertado: “O mundo que se desmunda aí está / à espera de aragem sagrada de vossas bocas / dizei um novo Atharva-Veda poetas oficiantes / buscai o ponto de união de tantos cacos / dispersos" (Silva, 1999, p. 402). Como se poderá observar mais à frente, a poeta é, como Jung, "espiritual", daí que sua poesia sobre o mundo caótico seja a de lançar as bases para a reedificação, de empregar os recursos linguísticos no construto poético de forma análoga à construção de um novo habitat. A cada poema novo, uma nova morada, mais alegre, mais acolhedora.

Vemos aqui, novamente, a reverberação da poética hölderliniana no propósito poético de Dora, para quem, assim como o poeta alemão, "Cheio de méritos, mas poeticamente, vive o homem sobre esta Terra" (Hölderlin, 2000, p. 209). O poeta, ao nomear em medida humana o que se the revela em desmedida sagrada, funda, poeticamente, a habitação humana como possibilidade de que haja mundo, instituído a partir da abertura configurada pelo dizer autêntico do poema.

O mundo fundado pela arte procura harmonizar, sem que se eliminem as tensões, ordem e caos originário. Nesse sentido, Novalis, filósofo-poeta de grande ascendência sobre Dora Ferreira da Silva, reabilita no romantismo alemão a arte como cura, não no sentido medicinal de eliminação de doenças, mas de unificação da dor e seu avesso, do prazer e do desprazer, da saúde e da doença, recobrindo a poesia de propriedades salvíficas:

Poesia é a grande arte da construção da saúde transcendental. O poeta é portanto o médico transcendental. A poesia reina e impera com dor e cócega - com prazer e desprazer - erro e verdade - saúde e doença - mescla tudo para seu grande fim dos fins - a elevação do homem acima de si mesmo (Novalis, 2009, p. 123).

A saúde do equilíbrio em que o homem se eleva acima de si mesmo será resgatada anos mais tarde por Carl Gustav Jung, no campo da psicologia, e por Dora, na poesia, que não se identifica com a aridez e a solidão de obras como Ulisses, feita, segundo Jung, para aqueles de tal modo atingidos pela insensibilidade que já não esperam por redenção.

\section{Os livros e a vida: Nada tens a dizer agora}

Desde os primeiros registros da literatura arcaica, a poesia envolve um sentido de organização e ordenação do universo, provocando um impacto positivo sobre a vida das pessoas, o que muito cedo lhe coube o epíteto de humanizadora do homem. Apolo, deus que preside as artes, a poesia e a música, é o grande civilizador da cultura grega, pois sua essência consiste, segundo Junito Brandão (2008), em "desbarbarizar" as tradições, porque seu culto renovou o pensamento sem abolir os contrários, buscando harmonizar as tensões dionisíacas por meio do equilíbrio e da moderação. A importância da arte na vida social pode ser medida, ainda, pelos Jogos Píticos em louvor de Apolo, opondo-se aos Jogos Olímpicos, que ocorriam em Delfos. Os Jogos Píticos dedicavam-se "às disputas musicais e poéticas" (Brandão, 2008, p. 93). Nos versos finais de O hino homérico a Apolo, o deus surge como aplacador das angústias e acolhedor das diversidades:

tolos homens, que andais infaustos a campear angústias

doloridas, lavras e tristuras para vosso coração.

Fácil vos dou a resposta; e na vossa alma a gravarei:

[...]

vigiai o templo, e acolhei dos homens toda estirpe

que sob o meu desejo virão aqui se concentrar

quando palavra houver ou ato descabido

ou mesmo agravo: como é praxe entre os mortais. 
Outros homens, depois desses, como líderes tereis

e com a força deles, obedientes heis de ser (Cabral, 2004, p. 167-169).

A poesia de Dora Ferreira da Silva, plena da vitalidade e musicalidade dionisíacas, é harmonizada por Apolo, que organiza os sons guturais e desmedidos da inspiração, incidindo sobre o construto poético a purificação da luz racional: "A irrupção do Poema é o silvo que Apolo harmoniza e Orfeu faz cantar" (Silva, 2004, p. 28). A arte só podia se originar dos raios quentes e brilhantes do sol, que encerram o poder da clareza e da vida animada, atributos logo designados à poesia, ela mesma avatar desses poderes: "Quando se afasta, pássaros silenciam e a fonte / em Delfos quase se extingue. Lobos uivam. / Imensa é a noite fria em sua ausência" (Silva, 2004, p. 28). Da luminosidade apolínea, da presença luminosa da divindade em que ordem apolínea e caos dionisíaco se equacionam, nascem seja a palavra oracular da fonte délfica, seja o canto órfico, os quais só em face da presença sagrada nomeada subsistem.

Mas nenhum semideus operou tanto prodígio, com sua arte, entre os mundos e os homens, como Orfeu, o célebre filho de Apolo. Quando a poesia está em jogo, os tormentos cessam. É assim com a presença de Orfeu no Hades: primeiro, conseguiu acalmar Cérbero, o feroz cão tricéfalo guardião dos portões dos mundos ínferos; depois, na iminência de ser aniquilado por Hades e Perséfone, sem ao menos explicar-lhes sua ousadia, toma da lira e começa a projetar, com suas palavras, vida sobre a escuridão, argumentando que, apesar do caos do mundo infernal, cheio de medo, silêncio e confusão, ainda era cedo para uma jovem morte: "por estes seus domínios / Tão cheios de medo, esta imensa confusão, / Pelo silêncio que impera em seu vasto reino, eu lhes imploro, / Recriem a vida de Eurídice, que lhe escapou cedo demais" (Ovídio, 2003, p. 202). Ao reconstituir em versos seu amor por Eurídice, causa uma grande comoção no Senhor dos Infernos que, tempos antes, privado de seu amor pela sobrinha, fora levado a raptá-la. Canta Orfeu que, se não levar a esposa, prefere morrer também: "eu estou pedindo / Um empréstimo, e não um presente. Se o destino negar / Esse privilégio para minha esposa, uma coisa é certa: / Eu também não quero voltar; triunfaremos / Os dois na morte" (Ovídio, 2003, p. 202).

Hades se identifica com a história da perda, da transgressão dos códigos em nome do amor, e autoriza Orfeu a trazer Eurídice de volta ao mundo dos vivos. Certamente, Hades também se angustia a cada subida de sua esposa para visitar a mãe, temendo o seu não retorno. Aqueles versos pungentes de Orfeu, lamentando a ausência de Eurídice, que reverberavam nos subterrâneos da escuridão, resgatando experiências pessoais de Hades e comovendo-o, também interromperam as repetições torturantes das almas que viviam ali sob duras penas, em suplícios intermináveis:

Suas palavras e sua música

Fizeram os pálidos fantasmas chorar: a roda de Ixion

Ficou parada, os abutres de Titios pararam de comer seu fígado,

Tântalo não mais tentou chegar até a água.

As filhas de Belo descansaram em seus túmulos,

E Sísifo subiu numa rocha para ouvir o poeta e músico.

Essa foi a primeira vez, no mundo inteiro,

Em que as Fúrias choraram. Nem o rei nem sua consorte

Tiveram autoridade suficiente para negar o que ele pedia,

Então a chamaram,

Eurídice (Ovídio, 2003, p. 202).

O pungente mito de Orfeu conheceu muitas versões, mas a que ficou eternizada foi a de Ovídio, porque intensifica os sentimentos inatos ao homem que constituem a essência desse mito: o amor, a morte e o poder da palavra de interferir no universo, harmonizá-lo. Nos versos da poeta contemporânea Dora Ferreira da Silva, quando Orfeu recolhe sua lira, inconsolado pela morte de Eurídice, o mundo se cobre de trevas, definha e o bem cessa de jorrar: "A erva sem flores / vazios os ninhos o canto emudece. / Folhas resistem ao vento / e na cabana do lenhador o pão endurece" (Silva, 1999, p. 307). Mas o poder fundante da palavra poética entrelaça homem e natureza, expressando vivências, sentimentos, libertando a alma do homem aprisionada pelo racionalismo e pela opacidade das coisas contempladas de forma objetiva. Tal impressão de vida e sentimentos é o que provoca o canto de Orfeu no mundo sombrio: 
O infecundo fecunda-se, abrem-se pétalas,

intumesce o caule da lira adormecida - sua floração

desponta e craveja as trevas com seu pólen.

Choram as pedras. Ao áspero, ao inerme

a música tange e enleia.

Em procissão arrasta árvores raízes ao ar pássaros,

do sono desperta os metais;

move-se o todo elos de uma só corrente:

rochedos, áspides dóceis à amorosa lira (Silva, 1999, p. 308).

Fecundar a vida, enchê-la de alegria e brilho, animar a matéria fria, eis o poder da palavra já entrevisto no romântico Novalis: "Amigos, o chão está pobre, precisamos espalhar ricas sementes / Para que nos medrem colheitas apenas módicas" (Novalis, 2009, p. 36). Não sendo solução definitiva, dado que a colheita é módica, Dora aposta na ideia hölderliniana de que só poeticamente o homem pode habitar e se preservar de maneira humana nesta Terra. Nesse sentido, a poeta harmoniza as contradições, buscando restaurar no cosmos sua origem primordial em que pedras, homens e serpentes são "elos de uma só corrente". Esse manejo poético da palavra só se atinge, segundo Novalis, quando a linguagem é colocada a serviço do espírito como potência de nomeação poética:

A designação através de sons e traços é uma abstração admirável. Quatro letras me designam Deus; alguns traços um milhão de coisas. Quão fácil se torna aqui o manejo do universo, quão visível a concentricidade do mundo dos espíritos! A gramática é a dinâmica do reino dos espíritos. Uma palavra de comando move exércitos; a palavra liberdade nações (Novalis, 2001, p. 36).

Antes mesmo da crise da eficácia da linguagem, que gradualmente esvaziou os poderes da palavra poética e destituiu sua ligação ao horizonte do Sagrado, seja em perspectiva terrena ou transcendente, a poesia, antiga forma de profecia, já se calava na boca de Cassandra, aquela que conseguia profetizar mas, amaldiçoada por Apolo, não era levada a sério. Aos ouvidos do povo, suas palavras não passavam de delírios, sonhos mal recolhidos da noite que não traziam verdade, que eram apenas sentenças mal compreendidas, que não tinham poder de interferir na realidade. Tentou, desesperadamente, alertar seu povo sobre a invasão grega. A voz de Cassandra se perdia nos ecos das praias de Troia, não conseguindo, portanto, evitar a destruição do império. Semelhante impotência do verbo poético é experimentada nos versos seguintes:

Não, Cassandra...

Não, Cassandra nada tens a dizer agora

dorme em paz. O Nada como a terra se encharca

à espera. Não firas o silêncio com punhais

de negras profecias. Há sementes à beira do acordar.

Se não calares como ouvir o vento?

Ele dirá onde nascimento houver.

Não prodigues em desatino guerras antigas

explosões de amores cego destino. Cassandra,

o silêncio é lento e de musgos. Vai com a noite

descansa... Descalças virão crianças só para ouvir

como canta um pássaro e árvores despertam.

O céu baixou a pálpebra cinzenta: convite ao sono

para ti, exaltada. Dorme. E ao acordares pergunta

ao novo dia onde onde estás (Silva, 1999, p. 312).

A palavra "agora", no princípio do poema, remete o leitor para a temporalidade mítica e para o espaço da subjetividade articulada a esse tempo. Sobre o mito, que trata do esvaziamento da palavra profética por opção dos homens: Cassandra negou-se a consumar o amor prometido a Apolo, e ele cuspiu em sua boca, amaldiçoando-a. Abandonada pelos 
deuses, Cassandra não consegue ser ouvida, e os muros de Troia caem e a cidade experimenta a ruína. Sem a chancela do divino, a palavra perde seu poder.

No poema, o sujeito lírico se embute no "tu" intratextual da personagem mítica, tomando para si - vivenciando - a mesma experiência traumática de proferir uma palavra sem sentido. $O$ "agora" é tempo da exaltação estéril, em que se proferem profecias negras ferindo o silêncio.

Mas é também nesse "agora" que o sujeito lírico, sobrepondo-se à mesma Cassandra a que se endereça, conclui pela necessidade do nada e do silêncio como possibilidade da pergunta pelo novo dia em que a palavra venha à luz. Antes de começar a falar, é preciso se esvaziar de si, buscar o Nada - potência máxima da mística - envolver-se de silêncio para ouvir a natureza e depurar a palavra. Árvores e pássaros são a nova voz oracular, e é por meio deles que o homem moderno deve reaprender a ouvir a voz sagrada. No vento e nos musgos estão o sopro divino que reanima a natureza, enchendo os versos de recado, e o tempo necessário à criação. Por meio do labor da organização poética que homologa palavra e coisa, personagens, tempo, guerras e os amores antigos se atualizam na poesia e na vida do leitor. Espaços e fronteiras, dessa forma, se diluem, se unificam, formando uma só unidade, o novo dia do Poema.

\section{Os livros e a vida: um brilhante produto do inferno}

Em "Ulisses - um monólogo", do livro O espírito na arte e na ciência, Carl Gustav Jung relata suas dificuldades de leitor diante da obra monumental de James Joyce, não omitindo que as primeiras tentativas de leitura, em 1922, foram fracassadas: "ao chegar à p. 135, mergulhei definitivamente num sono profundo, isto após diversas tentativas heroicas para aproximar-me do livro" (Jung, 1991, p. 96). Dora Ferreira da Silva foi tradutora de Carl Jung. Se a confissão inicialmente desconcertante do psicólogo sobre Ulisses encorajou a poeta a manifestar em "Ulisses e o inseto" seu desinteresse pela obra joyceana, nenhuma aproximação comparativa, em termos de influência, entre o poema e o artigo seria de interesse para este trabalho, uma vez que Jung elabora uma teoria sobre o fenômeno do impacto do livro sobre a vida das pessoas, ao passo que Dora aponta, sinteticamente, seu caminho poético de abertura cósmica que lê a vida como enigma, e isso basta naquele momento de expressão poética.

A história do artigo de Jung sobre o Ulisses é bastante curiosa: um editor alemão ouviu a palestra de Jung "A psicologia do poeta" e acreditou que o estudioso escrevera pensando na obra de Joyce. Então, solicita ao psicólogo um artigo para a edição de uma revista literária, cujo tema versaria sobre o Ulisses e seu autor. No referido artigo, Jung teria emitido opiniões "de maneira bastante rude", deixando o editor em um fogo cruzado: amigos de Joyce pediam para o texto não ser publicado; por sua vez, Jung insistia na publicação, ao passo que o próprio Joyce fazia questão de que a crítica viesse à luz e em posição de destaque, para que todos pudessem tomar conhecimento. Esta primeira versão não é conhecida, nunca veio à luz.

Anos mais tarde, em 1932, Jung retoca o artigo, revelando com honestidade o tédio que a obra lhe causou, a ponto de mergulhar em um sono profundo, mas encontrando na obra um juízo de valor estético altamente positivo, conforme se verá. A primeira queixa de Jung é que nas 735 páginas da obra não há "nenhuma ilha de paz e felicidade", de um "vazio sufocante ou irrespirável", adensado pela ausência de pontuação das últimas páginas: "este vazio inteiramente sem esperanças é a nota dominante de todo o livro. Ele não só começa e acaba no nada, mas também consiste apenas de nadas" (Jung, 1991, p. 95). Enfim, Ulisses é "um brilhante produto do inferno". Jung alega, ainda, que nenhuma expectativa se cumpre nas 735 páginas de "efeito monótono e hipnótico", cabendo ao leitor não esperar nada para atenuar a tortura. Após dormir à página 135, descobre que o livro pode ser lido "de trás para diante". Por fim, o crítico elogia a capacidade que Joyce tem de fazer entrelaçar as figuras objetivas das ruas de Dublin com infinitas associações subjetivas. Mesmo evocando a inutilidade da obra de arte defendida por Oscar Wilde, Jung acentua que qualquer leitor espera algo de "essencial" de uma obra, por isso sentiu-se ludibriado e ofendido, tomado por "irritantes sentimentos de inferioridade". Pontua que o autor foi descortês e despertou sua má vontade, ao colocá-lo "diante da própria burrice". 
Ofendido, entediado, desconfia "que Joyce nada quisesse representar", uma vez que o romance todo "é levado por uma corrente subterrânea vívida", resultado de uma organização e de uma intenção, não sendo jamais "um produto de esquizofrênico". Esta percepção abre o caminho para Jung ler Ulisses dentro da perspectiva que lhe é mais cara a obra como uma manifestação coletiva do tempo:

$\mathrm{O}$ artista não obedece a um impulso individual mas a uma corrente coletiva, que, na verdade, não se origina diretamente do consciente, mas do inconsciente coletivo da psique moderna. Como se trata de uma manifestação coletiva, ela atua de modo idêntico nos mais diversificados terrenos, tanto na pintura como na literatura, na escultura e na arquitetura (Jung, 1991, p. 102).

O artista pratica a fragmentação da técnica artística para mostrar a "unidade de sua personalidade artística". Quando o artista distorce o sentido da beleza do mundo, oferecendo um produto desconcertante, ele o faz direcionado por um "propósito criativo", de alto valor espiritual. Então, se reclamamos quando Ulisses insulta nossos sentimentos e faz desmoronar a tradição da harmonia, continua Jung, estamos nos queixando de algo que é "fruto do ressentimento do 'antiquado' em nós, que não quer ver o que 'os deuses' ainda ocultam magnanimamente" (Jung, 1991, p. 103). Jung ressalta a magistralidade do romance, que abalou as convicções ainda conservadoras em relação às formas da arte que se ocupam do lado infernal da vida no início do século XX.

Nos ensaios "Relação da psicologia analítica com a obra de arte", de 1922, e "Psicologia e poesia", de 1930, o psicólogo concebe o artista como o andarilho que caminha por estradas desconhecidas, aquele que, por palmilhar caminhos inusitados, descobre coisas mais profundas, ouve cantos enigmáticos. Cabe-lhe, então, a responsabilidade de converter em imagens "legíveis" sensações, visões e pressentimentos que o homem comum experiência de maneira inconsciente, mas sem a intensidade que uma obra de arte, configurada conscientemente, é capaz de provocar.

A arte moderna, prossegue Jung, "a arte do avesso ou o avesso da arte", em sua desintegração criativa, ajuda o homem a se situar no caos da vida moderna, "levando velhos ideais à derrocada", promovendo a libertação do homem "do jugo do velho mundo" (Jung, 1991, p. 103). Esse livro surgido da "região dos mortos" presta-se, portanto, a resgatar os que ainda vivem espiritualmente presos à opressão medieval, sem forças para olhar o lado sombrio do mundo. A aridez e insipiência do mundo moderno é o que provoca as pessoas a encontrar luz e conforto no mundo de Ulisses, prossegue Jung, graças ao arranjo estético que oferece, ainda, a insensibilidade em oposição aos sentimentos falsos que se mostram abundantemente na modernidade. Desta forma, Ulisses é uma "insensibilidade" compensadora, o que alça James Joyce à condição de profeta:

O artista é sem querer o porta voz dos segredos espirituais de sua época e, como todo profeta, é de vez em quando inconsciente como um sonâmbulo. Julga estar falando por si, mas é o espírito da época que se manifesta e, o que ele diz, é real em seus efeitos (Jung, 1991, p. 107).

Conclui Jung que a obra é uma "consciência desprendida" da confusão que assola o homem, sendo necessário considerar que Joyce não tinha nenhum motivo para pintar um mundo alegre quando escreveu Ulisses, entre 1914 e 1921. O Ulisses de Joyce é um homem que se libertou do sentimento e do "deslumbramento", por isso o livro deve ser visto positivamente. Tomando consciência de que o mundo é nulo em espírito, o homem se transfigura. Após essas considerações, conclui: "agora a leitura do Ulisses já consegue ser bastante suportável" (Jung, 1991, p. 116).

A inquietação que moveu Jung a escrever sobre esse livro era saber porque algumas pessoas podem encontrar algum conforto nessa obra de aridez, solidão e nada. Onde viu, primeiramente, excesso estilístico e desorientação semântica, onde havia mera significação, Jung encontrou o arquétipo de uma época. Tal como postula Wolfgang Iser, o leitor entrou no jogo do texto, conseguiu olhar para o lado sombrio do mundo, porque o mundo da ficção ainda é melhor que o mundo real. A redenção para quem está oprimido é poder encontrar um mundo parecido com o seu, mas passível de ser transformado pela imaginação. 


\section{Os livros e a vida: o jogo como simbolização da vergonha e a coisa mais vergonhosa}

No ensaio "O jogo do texto", Wolfgang Iser (1979) potencializa a intervenção do leitor na configuração mimética do texto, afirmando que o sistema aberto dos tempos modernos permite uma atuação no processo textual dentro de uma postura performativa, similar a um jogo: o leitor conhece as regras, sabe que o texto é uma ficção criada por seu autor, mas, ele mesmo, o leitor, vai imprimindo um outro sentido ao texto, uma vez que a imaginação e a interpretação acionadas durante a leitura operam uma transgressão no texto, destronando aquele mundo que poderia ser "real". Por isso, Iser fala de um "significante fraturado" no texto, que provoca um movimento de avanço e recuo em relação ao que é em seu espaço, consistindo o jogo em apontar para o sentido que o autor cria e o que o leitor recria: "Assim o significante fraturado - simultaneamente denotativo e figurativo - invoca alguma coisa que não é pré-dada pelo texto mas engendrado por ele, que habilita o leitor a dotá-lo de uma forma tangível" (Iser, 1979, p. 110). Desse modo, cada leitor, individualmente, cria o cenário do texto, atualizando-o a cada releitura, uma vez que há uma necessidade humana de se aproximar das experiências que lhe são dadas, porque isso faz o leitor ganhar experiência. Abrir-se ao não familiar é uma defesa, uma preparação para enfrentar o imprevisível.

Nos jogos, a encenação do jogo presentifica a situação ausente, e a transformação encenada é tão somente um jogo. De igual modo, o texto atende à necessidade antropológica de "conceber aquilo que nos é recusado" (Iser, 1979, p. 110). Desta forma, tem uma explicação para o ritual das festividades em louvor a Dioniso, quando os participantes faziam procissão carregando falos, para saudar a fertilidade, a vida e também a orgia. Os devotos reencenam um mito antigo:

Dioniso desejava ansiosamente descer ao Hades mas ignorava o caminho; um certo homem, de nome Prosymnos, promete então explicar-lhe, mas não sem uma paga; uma paga desagradável, mas para Dioniso agradável: os prazeres do amor, eis a paga pedida a Dioniso. De bom grado o deus acolhe o pedido e promete satisfazê-lo quando retornar, confirmando a promessa com um juramento. Ensinado o caminho, ele vai; retorna mas não encontra Prosymnos (pois morto estava). A fim de quitar a dívida para com o seu amante, atira-se Dioniso sobre seu túmulo a saciar-lhe o desejo. Corta ao acaso um ramo de figueira ao que dá a forma de um pênis e assenta-se sobre ele, cumprindo sua promessa ao morto. Em mística lembrança a esse fato, são dedicados falos a Dioniso nas cidades (Heráclito, 2012, p. 49).

O excerto de Clemente de Alexandria, Exortação, 34,5, é finalizado com o seguinte comentário de Heráclito: "se não fosse para Dioniso a procissão que fazem e o hino que entoam com as vergonhas, realizariam a coisa mais vergonhosa" (Heráclito, 2012, p. 49). No contexto exposto, claro está que a situação ficcional enseja a vivência pela representação, permitindo ao homem vivenciar na ficção a experiência do que, a dado momento e em uma cultura específica, lhe é interditado como prática não ficcional.

\section{Os livros e a vida: como num friso do Parthenon}

Poeta de larga erudição, Dora Ferreira da Silva escolheu a via do sagrado para acessar a arte, projetando sobre o mundo dos livros e da vida uma intensidade de vivência humana inseparável de seu pensamento. Celebra ao longo de sua obra sua afeição e reconhecimento por autores e personagens da literatura universal, deixando um pequeno mapeamento que mostra bem a ascendência daqueles "amigos amigas" em sua obra e em sua vida de leitora, tradutora e ensaísta: "Amigos amigas: estrelas / de luminosas constelações / benévolas - porque imensas / a música mais bela que escutamos / ao apagarmos a luz para sonhar. Cintilam / amigos amigas reais imaginários" (Silva, 1999, p. 377). São escritores que fazem parte de sua "família espiritual", isto é, são os eleitos a partir de uma afinidade que a motivou a estar sempre próxima a eles nas atividades intelectuais, seja para leitura, tradução e/ou palestra. São citados: Blake, Poe, Emily, Donne, Rimbaud, Eliot, Rilke, Hölderlin, Yeats, "Mestre Guima, bardo de minha / predileção. Drummond de Andrade - poeta grande / guia e professor" (Silva, 1999, p. 377-378). Se compreendemos o sonho no sentido bachelardiano, isto é, o devaneio, são esses 
autores - e seus universos poéticos - que reverberam em sua imaginação. No segundo poema, a poeta explica como é sua vivência com os ícones literários:

Amigos Amigas II

Assim como num friso do Parthenon

estão meus amigos amigas

acaso num banquete. De longe os admiro

com amizade imperecível. Os que conheci não conheci

lá estão. Livros e emoções que a arte inventa

personagens do Morro dos Ventos Uivantes

também acenam. É Heathcliff, sem dúvida, aquele à esquerda.

Chamo-os em voz baixa quando estou sozinha

eles nunca dizem não. São delicados

já fruíram a grande solidão e um colóquio amigo

os interessa. Descartado o gosto do lamento

ponho o melhor vestido, sóbrio ou requintado,

componho o penteado de cachos ou trançados

de flores adorno a sala de visitas.

Perfumada de alegria os espero. Ouvimos

nossos pensamentos na penumbra da sala

onde a rosa vermelha exala solidão (Silva, 1999, p. 378).

Ainda uma vez Dora Ferreira da Silva vai buscar na cultura grega uma experiência para expressar sua relação com a arte, uma imagem que representa o impacto em sua vida dos "Livros e emoções que a arte inventa". O universo ficcional se lhe afigura como o friso do Parthenon na Acrópole de Atenas: como os homens, animais, guerreiros e mulheres, eternizados nas esculturas em toda sua vivacidade, lançando um fio entre o presente e o passado, entre o real e o imaginário, assim são as personagens dos livros que a poeta admira: rompem as paredes do templo/livro e, em sua eterna mudez, beleza e perfeição, entram na sua intimidade, fazem-lhe companhia, atendem ao seu chamado de solidão. As personagens que ficam são aquelas bem talhadas em matéria e espírito, que se fazem vivas em cada detalhamento pela habilidade de seus autores, como se pode dizer dos frisos do Parthenon, que são "a mais bela arte do mundo", conforme Jonathan Jones:

Tem uma vida, energia, calma e grandeza que lhes são próprias. As figuras das deusas reclinadas, no frontão leste, por exemplo, são sínteses espantosas mas fluidas de massa e graça, mais sonhos que objetos. As veias que pulsam nos flancos equinos de um centauro, o sofrimento dos animais mugindo aos céus enquanto são conduzidos ao sacrifício (Jones, 2014).

Como as personagens do friso do Parthenon, que se prestam a longas contemplações fazendo-se presentes em quem as contempla, as personagens livrescas se movimentam na imaginação, são íntimos desconhecidos que entram em comunhão com quem deles se acerca. Isolados em seus espaços, leitor e personagens ficariam presos cada um em suas desventuras. Mesmo o atormentado Heathcliff, agora apaziguado e reconciliado consigo mesmo, atende ao aceno, se presta à comunhão.

\section{O livro sem a vida: Não valerá uma folha de primavera}

Ao final da apresentação do número 3 da Cavalo Azul, Dora Ferreira da Silva postula que "toda obra de arte é uma confissão", quando o artista pode optar por promover a liberdade e a comunhão em vez de pactuar-se com a solidão e o cárcere, daí o temor de Platão pelo artista, porque a arte pode edificar ou destruir o mundo:

Confessando-se na obra de arte, espelhando o divino ou sua carência, o homem, além de espelhar-se, cria ou destrói seu tempo, seu mundo. A obra de arte inócua não é obra de arte. Não valerá uma folha de primavera. Por que temia Platão o artista, a ponto de exilá-lo de sua república? Há um poder aliciador na obra de arte, capaz de arrancar o mundo às 
suas formulações. Assim, dado o Poema inicial de um mundo, os demais poemas nele inscritos serão repetições ou sementes destruidoras (Silva, s/d, p. 2).

Em perspectiva próxima à de Jung, Dora entende serem as obras de arte reflexos do universo e da aventura humana no espaço e no tempo. De seu ponto de vista, as obras de arte são celeiro das contradições, dificuldades, carências, desequilíbrios, mas também representam as alegrias, esperanças e crenças, tudo o que emana e faz da arte um mapa do "espírito do tempo". As potências da arte são, nesse sentido, arquetípicas. Sendo o livro derivado das vivências humanas mais arcaicas, aquelas que se alojam na psique, nos livros o humano está sempre se refazendo em "vestes renovadas".

\section{Referências}

BRANDÃO, Junito (2008). Dicionário mítico-etimológico. Petrópolis: Vozes. v. 1.

CABRAL, Luiz Alberto Machado (2004). Hino homérico a Apolo. Cotia: Ateliê; Campinas: Editora da UNICAMP.

HERÁCLITO (2012). Heráclito: fragmentos contextualizados. Tradução, estudos e comentários de Alexandre Costa. São Paulo: Odysseus.

HÖLDERLIN, Friedrich (1999). Elegias. Lisboa: Assírio \& Alvim.

HÖLDERLIN, Friedrich (2000). Hinos tardios. Lisboa: Assírio \& Alvim.

ISER, Wolfgang (2002). O jogo do texto. In: LIMA, Luiz Costa (Org.). A literatura e o leitor: textos de estética da recepção. São Paulo: Paz e Terra. p. 105-118.

JONES, Jonathan (2014). Frisos do Parthenon são a mais bela arte do mundo... Folha de S. Paulo, São Paulo, Caderno Ilustríssima, 22 ago. Disponível em: https:/ / bit.ly/2VAbQBX. Acesso em: 14 jun. 2018.

JUNG, Carl Gustav (1991). O espírito na arte e na ciência. Petrópolis: Vozes.

NOVALIS (2009). Pólen. Tradução, apresentação e notas de Rubens Rodrigues Torres Filho. São Paulo: Iluminuras.

OVÍDIO (2003). Metamorfoses. São Paulo: Madras.

SILVA, Dora Ferreira da (2004). Hídrias. São Paulo: Odysseus.

SILVA, Dora Ferreira da (1999). Poesia reunida. Rio de Janeiro: TopBooks.

SILVA, Dora Ferreira da (s/d). Cavalo Azul 3. São Paulo: Edição da Autora.

\section{Nota}

O presente trabalho foi realizado com apoio da Coordenação de Aperfeiçoamento de Pessoal de Nível Superior - Brasil (CAPES) - Código de Financiamento 001. 